\title{
Written Simulation of Patient-Doctor Encounters. 1. Research Instrument for Registration of the Performance of General Practitioners
}

\begin{abstract}
I M KUYVENHOVEN, H M JACOBS, FW M M TOUW-OTTEN AND J C VAN ES
- Uuyvenhoven M M (Depertment of General Practice, University of Utrecht, Mariahook 6, 3511 LD Utrecht, The Netherlands), Jacobs H M. Touw-Otten F W M M and van Es J C. Written simulation of patientdoctor encounters. 1. Research instrument for registration of the performance of general practitioners. Famity Practice 1984, 1:

A written simulation of patient-doctor encounters is described, involving five patients with vague complaints, an 'instruction' patient with sinusitis and a 'test' patient with acute appendicitis. Nineteon general practitioners were confronted with it. The extent to which the simulation distorted reality and the implications of such distortions were considered in an attempt to assess the content validity. The conclusion was that the simulation gave a realistic impression of the general practitioners' diagnostic and therapeutic approach to patients with vague complaints. The serching procedures in relation to the complaint and the patient's perception of the complaint were adequately depicted, and the therapeutic procedures approximated closely to reality. There was some distortion in the attention paid to psychosocial aspects as these were given more attention in the simulation than they receive in reality.
\end{abstract}

Simulation is a useful method for recording and comparing the performance of physicians. It is - ssible to confront them with identical patients ad situations and to compress a process which brmally covers a longer period of time. The written simulation developed in the Department of General Practice, University of Utrecht, relates to patients with common, non-acute complaints such as low backache and lower abdominal pain. The general practitioner faced with complaints of this type is expected to decide whether they represent symptoms of a serious condition or problems of minor importance; many vague complaints are symptomatic of selflimiting diseases or other problems with which the patient can learn to cope.

The simulation comprises a test patient with acute appendicitis-an acute somatic problem of minor complexity-which is nearly always identified and treated correctly in reality. ${ }^{1}$ The

Department of General Practice, University of Utrecht, Mariahoek 6. 3511 LD Utrecht, The Netherlands. test patient was used to establish whether the 19 general practitioners identified acute appendicitis and treated the patient accordingly and if, as in reality, there were differences in the diagnostic and therapeutic procedures with the five other patients. In this way the content validity of the simulation is described.

The 19 general practitioners were interviewed after the encounter to establish their subjective experiences-whether they recognized themselves as general practitioners in the simulation, perceived the patients as true to life and used their normal diagnostic and therapeutic procedures.

\section{METHOD}

Simulation setting. This was a room furnished and equipped like a surgery in which the practitioner had access to the things available to him in normal practice: the records of the patients and their families, stationery, prescription pad, authorizations, forms for requesting laboratory and radiological work, and reference books. 
Patients. Five simulated patients with common, non-acute complaints were prepared (patients A, B, C, D, and E in Table 1). In addition to these five patients there was an 'instruction' patient with sinusitis and a 'test" patient with acute, severe somatic signs and symptoms clearly recognizable as acute appendicitis. They were all assumed to be recently registered patients with a complaint not previously presented, enabling the physician to enter into the encounter with an open mind. Real patients were used as guidelines.

Test group. Nineteen general practitioners 'rom the province of Utrecht participated in the yudy. On 31 December 1978 they had been Stablished in practice for at least five years and all were less than 60 years old. No practitioners actively involved in the vocational training programme were included, lest the prejudices and attitudes of the department should cause distortions in their performance.

Simulated encounter. The general practitioners began each encounter by reading an introductory description of the patient and the complaint. The introduction for patient $\mathrm{A}$, for example, read as follows:

A woman aged 28 years enters your surgery; you do not know her. She is of normal appearance, friendly and gives no impression of ill health. She tells you that she moved here from Zwolle three months ago. Stie is married and has a son aged five years. Her hushand manages the offict of a garage firm. When you ask why she has come to see you, she says, 'My tummy is bothering me again.'

The history was taken and the examination made by choosing options formulated as questions. These questions, presented in the form of a 'menu card', were arranged under different headings: questions related to the presenting complaint, to other complaints, to the request for help, to self-medication, intrapsychic and psychosocial functioning, physical examination and laboratory findings such as urinanalysis and blood counts. Detailed information was obtained via categories of 'further questions'. The number of questions available was largesome 1000 questions and answers per patientbecause every general practitioner has his own way of searching for information. Moreover, general practitioners focus not only on complaint aspects but also on coping behaviour and intrapsychic and psychosocial functioning. ${ }^{2}$

All questions were numbered and the general practitioner asked questions by mentioning appropriate numbers. A practice assistant found the corresponding answer and gave this to the general practitioner. At the same time she noted the question number, playing a neutral, clerical role. The general practitioner was allowed to conclude the encounter whenever he wished and was asked to formulate a 'strategy' by recording on tape what he would have told a real patient. If he considered it necessary, he could write a referral letter or a prescription. This form of

)

TABLE I The seven simulated patients in the order of the simulated encounters

\begin{tabular}{|c|c|c|c|c|c|}
\hline Patient & $\operatorname{Sex}$ & $\begin{array}{c}\text { Age } \\
\text { (years) }\end{array}$ & $\begin{array}{l}\text { Marital } \\
\text { status }\end{array}$ & $\begin{array}{l}\text { Number of } \\
\text { children }\end{array}$ & Complaint \\
\hline $\begin{array}{l}\text { Instruction } \\
\text { patient } \\
\text { (sinusitis) }\end{array}$ & Male & 28 & Single & None & Headaches during the past week \\
\hline A & Female & 28 & Married & One & Abdominal pain during the past 10 days \\
\hline B & Female & 36 & Married & Three & $\begin{array}{l}\text { Low back pain during the past two weeks, with } \\
\text { radiation to the right calf and foot during the past } \\
\text { two days }\end{array}$ \\
\hline $\begin{array}{l}\text { Test patient } \\
\text { (acute } \\
\text { appendicitis) }\end{array}$ & Male & 32 & Married & Two & Severe abdominal pain during the past few hours \\
\hline C & Female & 27 & Single & None & $\begin{array}{l}\text { Malaise-iike complaints during the past month, } \\
\text { with a history of similar episodes; left-sided } \\
\text { nephrectomy a' age seven years }\end{array}$ \\
\hline D & Male & 30 & Married & None & $\begin{array}{l}\text { Pain in the right elbow at the level of the external } \\
\text { epicondyle during the past six weeks }\end{array}$ \\
\hline $\mathbf{E}$ & Female & 41 & $\begin{array}{l}\text { Divorced } \\
\text { (6 months) }\end{array}$ & Three & $\begin{array}{l}\text { Fatigue, abdominal pain and irregular vaginal } \\
\text { blood loss during the past five weeks }\end{array}$ \\
\hline
\end{tabular}


concluding the encounter was seen as preferable to offering a series of therapeutic options.

Second encounter. Because the performance of the general practitioner depends on the course of the complaint, a second encounter was simulated. At the start of this second encounter the general practitioner received detailed feedback on his conclusion of the first encounter with the same patient. Since the patient had retursed with the same complaint, the information system in the second encounter was identical to that in the first. The second encounter followed the same day: thus time was compressed or 'telescoped'.

The 'instruction' and 'test' patients did not eturn for a second encounter, but the general fractitioner did receive feedback; both patients were always doing well, regardless of the policy adopted by the doctor. This feedback was intended as a stimulation at the start of the second series of encolinters.

Post-encounter interview. A semi-structured interview was held with the general practitioners after the encounters to elicit their experiences in the simulation. The questions focused on three aspects:

1. Whether they felt 'at home' in the simulation, that is, whether they recognized themselves as general practitioners and perceived the patients as true to life.

2. How they thought that their performance in the simulation deviated from their work in reality.

3. How realistic they found the second series f encounters.

buring the interview the recorded 'conclusions' of the encounters were played back to enhance the recall of the perceptions of the general practitioners; this is a form of stimulated recall. 4.5 The interviews were taped and subsequently coded.

\section{RESULTS}

\section{The Performance of the General Practitioners}

The 19 general practitioners all diagnosed acute abdomen or acute appendicitis in the test patient and referred this patient to a surgeon. Individual differences between the doctors were observed in the way in which the encounter was concluded. One doctor called an ambulance, for example, while another told the patient to go home and call a taxi for transport to the hospital.

The general practitioners used different diag- nostic and therapeutic procedures with the five patients who had vague complaints: some took an extensive, others a limited history; some paid much, others but little attention to the patient's perception of the complaint or to his psychosocial functioning. The differences in therapeutic procedure included differences in medication, referral and appointments for a second encounter.

For example, in his encounter with patient $A$. general practitioner 4 explored the possibility of synaccological, urological or intestinal problerns (Table 2). He asked the patient whether she was afraid of something serious and what she herseli thought might be wrong (complaint perception). HE also tried to establish whether her complaint was related to her psychosocial functioning. In the second encounter be continued this procedure. In the conclusions to the encounters he explained to the patient what seemed wrong with ber, prescribed spasmolytics and gave explicit instructions.

General practitioner 12 focused his history-taking and examination on digestive tract and urological problems. He explained to the patient that she was suffering from chronic irritation of the caecum and prescribed a spasmolytic drug. In the second encounter he placed the emphasis differently, asking some questions about the course of the complaint and paying much attention to her intrapsychic functioning. Concluding the encounter, he described the patient as rather listless and gloomy, and prescribed a neuroleptic drug.

The records of the performance of the 19 general practitioners in the simulation appeared to be highly realistic to other experienced associates of the department. The conclusion was that the simulation was realistic with respect to the differences in diagnostic and therapeutic procedures between the doctors and their performance with the test patient.

\section{The Experiences of the General Practitioners}

In the simulation the general practitioners recognized many of the feelings they experience in real situations. For example: 'To my mind, work in normal practice is exactly the same as here, but here it is more laborious." "I clearly recognize the same foelings of certainty and uncertainty.'

The practitioners formed a vivid mental picture of the simulated patients. For example, one remarked with regard to patient A: 'She somatizes and manoeuvres the physician into thinking that he has to solve the problem. She is 
TAluE 2 Summary of the searching and therapautic procedures of seneral practitioners 4 and 12 in two encounters with potient -.. A, the moman with abdominal complaints

General practitioner $4 \quad$ General practitioner 12

\section{Finst encounter}

Searchins procedures

History

Physical examination

Laboratory data

Cemplaint perception

Context complaint and f psychosocial functioning

Therapeutic procedures

\section{Second encounter}

Searching procedures

History

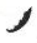

Physical examination

\section{Laboratory data}

Complaint perception

Context complaint and psychosocial functioning

Therapeutic procedures
Quextions about the nature of the complaint. digestive tract, uriary tract, senital apparatus, menstruation, visual acuity. history of the complaint

Inspection, auscultation, percussion, pelpation of the abdomen, stroke pain in renal compartment, "cough", rectal touch, vaginal touch and speculum examination. release pain

ESR, WBC, urixe: sediment

Questions like: 'af raid of something serious?": "What do you think of it?', etc. Questions about correlation of complaint with anxiety, love-making, moving house. holidays, woekend; what her husband thinks of it: relationship with husband, episodes of depression

Explains that her abdominal pain is caused by sparms of the colon, and that there is nothing acute. He prescribes powders for the next ten days to 'reduce these spasms' (prescription: extra. belladonnac 0.010 and papaverine $\mathrm{HCL} 0.030,30$ powders, 3 dd 1 after meals). He advises her to watch her temperature and to report back earlier if this should rise. He asks her to come back in ten days for a further talk, because he suspects that the change of environment, the housemoving, etc. may play a role in the recurrence of her abdominal complaint

Questions about the course of the pain, pattern of defaecation, eating habits, urinary tract, senital apparatus

Inspection, auscultation, percussion and palpation of the abdomen

-

About the same questions as in the first encounter

Explains that these complaints are known to correlate with nervousness and tensions. She has told him of occasional feclings of depression and listlessness. It would be of help if her psychological tensions would diminish; the pain would probably diminish as well. He emphasizes that the condition is troublesome but harmaless. He prescribes a diet (because this is now beins recommended) and pills with a more specific effect on the colon thin the powders previously described. He asks ber to report back after three weeks. He indicates that be considers tranquillizers unnecessary and that, if the pain persists, he may refer ber to an internist (prescription: Duspatal, 60 drastes, 3 dd 1 before meals, and a cellulose-enriched diet)
Queations about the type of pain, dipestive tract, micturition and other complaints

Inspection and palpation of the abdomen, relense pain and 'cough'

Urine: sodiment, blood in faeces

'Are you worried about your adomen?"

Tells the patient that there may be chronic irritation of the blind gut. He gives her a prescription (without further explanation): if the pain disappears with this medication, she need not worry; otherwise she should report back (prescription: papaverine HCL 0.030 . 3 dd 1)

Questions about the course of the complaint, micturition, and whether the interval between menstruations has changed

Palpation of the abdomen

'Do you often worry about your abdominal pain?'; 'Does the pain become worse when you worry about it?'

Questions about having problems, episodes of depression, low spirits, listlessness, crying bouts

Tells the patient that in his opinion the abdomen is not 100 bad: the pain is not always there and the blood is normal. He remarks that she is a bit listless and gloom): To stabilize her mood he prescribes tablet: (in addition to the tablers to keep the bowels quiet). He gives no instructions about the number of tabtets to be taken per day. He advises her to report back if the pain does not disappear (prescriprion: Orap, 10 tablets, I dd 1: papaverine HCL 0.030, 3 dd I) 
rather reticent, not frank. She seems rather dependent.' Nevertheless the physicians missed having the non-verbal contact and presence of the real-life patient. The lack of an existing doctor-patient relationship was not thought to be a problem.

Simulated history-taking, physical examination and laboratory work were sometimes more extensive than in reality, a finding which is in agreement with the reports of others, for example, Goran and colleagues. ${ }^{6}$ The large number of questions available cues the physicians to ask more, and more appropriate questions. ${ }^{3}$ The physicians' own impression was that in the simulation they asked more questions bf a psychosocial nature. The availability of many questions of this type as well as the relatively low pressure on time stimulated them to ask such questions. A tendency to display socially desirable behaviour may have played a role because some physicians appeared to suspect that the study focused mainly on the psychosocial aspects of their performance.

Whenever more questions were asked about somatic problems than there would be in reality they were mostly history-taking questions aimed at one particular facet of the complaint, rather than questions which explored several aspects. By asking more questions, the physicians were seeking a firmer basis for a diagnosis already made. Simulated physical examination seemed to be less different from reality.

At the interview detailed attention was paid to the experiences of the 19 practitioners in the becond series of encounters. It was felt that the patient's reason for returning for a second encounter was realistic, although sometimes a different outcome was expected. This means that the feedback was realistic. Some physicians found the fact that the information system in the second series of encounters was the same as the first rather problematic and this detracted somewhat from the realism of the method.

The general practitioners were entirely free to conclude the encounter whenever they wist.-d and could record what they would say to the patient in reality, without being offered policy alternatives. Thus the cueing problem was not important. After listening to the recorded conclusions of each encounter, the physicians confirmed that their therapeutic procedures in the simulation closely resembled those they used in normal practice.

\section{DISCUSSION}

The results described here form the first step towards validating a written simulation of patient-doctor encounters. The simulation reflects faithfully the diagnostic and therapeutic approach of general practitioners to patients with vague complaints. The searching procedures for the complaint and the patient's perception of the complaint are effectively depicted. The therapeutic procedures approximate closely to reality insofar as the general practitioner proceeds in a way that is more directive and complaintoriented than non-directive and patient-oriented. However, these directive and complaint-oriented aspects are extremely important in normal dayto-day practice. The attention given to social aspects is distorted, with a tendency towards giving them more attention than they receive in reality.

For some purposes a simulation is preferable to measurements made in actual practice because the course of the complaint can be telescoped into a short time. The behaviour of the physicians can be compared because they are confronted with identical patients. Practitioners and investigators find acted simulation (in which the 'patient' is played by an actor/actress) more lifelike than written simulation. ${ }^{7.8 .9}$ This method therefore plays an important role in medical teaching and examinations. ${ }^{10}$ Acted simulation is effective for measuring communicative as well as diagnostic and therapeutic skills. "However the interaction between actor and physician is not entirely controllable, whereas a written simulation provides a less distorted impression of the diagnostic and therapeutic performance of general practitioners although this method may be unsuitable for investigating communicative aspects of the doctor-patient relationship.

This written simulation differs markedly from simulations such as Patient Management Problems (PMPs), ${ }^{12.13}$ which are characterized by the use of therapeutic options and by "bridging' between the categories. 'Bridging' means that options are coupled so that, after selection of an option, the choice is restricted to a few alternatives or even a single alternative. Such a structure limits choice and can cause marked distortions when compared with diagnostic and therapeutic procedures in reality. For research into the performance of general practitioners confronted with common, non-acute complaints it is a disadvantage if the practitioner has insuf- 
ficient scope for his customary procedures. The written simulation described here leaves the physician entirely free to switch between categories and questions, and to conclude the encounter in a way which closely approximates reality: the cueing problem in the diagnostic and therapeutic procedures is thus greatly reduced, and this enhances the reality value substantially in comparison with PMPs.

The behaviour which is registered in this simulation provides basic material which can be evaluated in various ways, applying both implicit and explicit criteria (compare Hodgkin ${ }^{14}$ ). The second paper in this series analyses the performance of the 19 general practitioners in the Jimulation in more detail.

\section{ACKNOWLEDGEMENTS}

We are indebted to $\mathrm{Dr} C$. Spreeuwenberg, general practitioner and associate of the Department of General Practice, for his valuable and inspiring contribution to the planning and writing of this publication. In addition we thank the staff members and the 19 general practitioners who participated in the construction and testing of the simulation, in particular M. M. van Nunen, general practitioner in Hoensbroek. Finally we thank Dr J. G. M. Gerritsma and Dr J. A. Smal of the Department of Educational Development of the medical faculty, University of Utrecht, for their methodological advice on he construction of the simulation.
1 Howie J G R. Diagnosis-the Achilles heet? J R Coll Gen Proct 1972: 22: 310-315.

2 McWhinney I R. Problem-solving and decision-making in primary modical care. Proc $R$ Soc Med 1972; 65: 934-938.

3 McCarthy W A. An assessment of the influence of cueing items in objective examinations. J Med Educ 1966; 41 : $263-266$.

- Kagan N. Can technology help us toward reliability in infuencing human interaction? Educ Technol 1973; 13: 4 - -51 .

5 Kagan N. Influencing human interaction-eleven years with IPR. Can Counsellor 1975; 9: 74-97.

- Goran M J. Williamson J W, Gonnella J S. The validity of patient management problems. J Med Educ 1973; 48: $171 \cdot 177$.

' Dombal F T de, Horrocks J C, Staniland J A, Gill P W. Simulation of clinical diagnosis: a comparative study. Br Med J 1971: 2: 575-577.

- Elstein A S. Schulman LS. Sprafka S A. Medical problem solving: an analysis of clinical reasonins. Cambridge, Mass.: Harvard University Press, 1978.

- Norman G R. Feightner. J W. A comparison of behaviour on simulated patients and patient management problems. Med Edwc 1981; 15: 26-32.

10 Hannay D R. Postgraduate examinations for general practice in Canada and the United Kingdom. Lancel 1979; 2: 28 - 30.

"Boucher F G. Palmer W H. Page G, ef al. The evaluation of clinical competence. Can Fam Phys 1980; 26: $151-152$

12 McQuire C H, Solomon L M, Bashook, P G. Construction and use of written simulations. New York: Psychological Corporation, 1976.

13 Gerritsma J G M. en Smal J A. Schriftelijke patientensimulaties voor onderwijs, evaluaties en onderzoek. Medisch Contoct 1979; 34: 1217-1225.

i4 Hodgkin K. Evaluation in primary care. Update 1980; 20: $963-972$. 